\title{
Forbidden oxygen lines at various nucleocentric distances in comets
}

\author{
A. Decock ${ }^{1}$, E. Jehin ${ }^{1}$, P. Rousselot ${ }^{2}$, D. Hutsemékers ${ }^{1}$, J. Manfroid ${ }^{1}$, S. Raghuram ${ }^{3,4}$, A. Bhardwaj ${ }^{3}$, and B. Hubert ${ }^{1}$ \\ ${ }^{1}$ Institut d'Astrophysique, de Géophysique et Océanographie, Université de Liège, Allée du 6 août 17, 4000 Liège, Belgium \\ e-mail: adecock@ulg.ac.be \\ ${ }^{2}$ University of Franche-Comté, Observatoire des Sciences de l'Univers THETA, Institut UTINAM - UMR CNRS 6213, BP 1615, \\ 25010 Besançon Cedex, France \\ 3 Space Physics Laboratory, Vikram Sarabhai Space Centre, 695022 Trivandrum, India \\ ${ }^{4}$ Department of Physics, Imperial College London, London SW7 2AZ, UK
}

Received 14 June 2014 / Accepted 19 September 2014

\begin{abstract}
Aims. We study the formation of the [OI] lines - that is, $5577.339 \AA$ (the green line), $6300.304 \AA$ and $6363.776 \AA$ (the two red lines) - in the coma of comets and determine the parent species of the oxygen atoms using the ratio of the green-to-red-doublet emission intensity, $I_{5577} /\left(I_{6300}+I_{6364}\right)$, (hereafter the $\mathrm{G} / \mathrm{R}$ ratio) and the line velocity widths.

Methods. We acquired high-resolution spectroscopic observations at the ESO Very Large Telescope of comets C/2002 T7 (LINEAR), 73P-C/Schwassmann-Wachmann 3, 8P/Tuttle, and 103P/Hartley 2 when they were close to Earth $(<0.6 \mathrm{au})$. Using the observed spectra, which have a high spatial resolution $(<60 \mathrm{~km} /$ pixel $)$, we determined the intensities and widths of the three [OI] lines. We spatially extracted the spectra to achieve the best possible resolution of about 1-2", that is, nucleocentric projected distances of 100 to $400 \mathrm{~km}$ depending on the geocentric distance of the comet. We decontaminated the [OI] green line from $\mathrm{C}_{2}$ lines blends that we identified.

Results. The observed G/R ratio in all four comets varies as a function of nucleocentric projected distance (between $\sim 0.25$ to $\sim 0.05$ within $1000 \mathrm{~km})$. This is mainly due to the collisional quenching of $\mathrm{O}\left({ }^{1} \mathrm{~S}\right)$ and $\mathrm{O}\left({ }^{1} \mathrm{D}\right)$ by water molecules in the inner coma. The observed green emission line width is about $2.5 \mathrm{~km} \mathrm{~s}^{-1}$ and decreases as the distance from the nucleus increases, which can be explained by the varying contribution of $\mathrm{CO}_{2}$ to the $\mathrm{O}\left({ }^{1} \mathrm{~S}\right)$ production in the innermost coma. The photodissociation of $\mathrm{CO}_{2}$ molecules seem to produce $\mathrm{O}\left({ }^{1} \mathrm{~S}\right)$ closer to the nucleus, while the water molecule forms all the $\mathrm{O}\left({ }^{1} \mathrm{~S}\right)$ and $\mathrm{O}\left({ }^{1} \mathrm{D}\right)$ atoms beyond $10^{3} \mathrm{~km}$. Thus we conclude that the main parent species producing $\mathrm{O}\left({ }^{1} \mathrm{~S}\right)$ and $\mathrm{O}\left({ }^{1} \mathrm{D}\right)$ in the inner coma is not always the same. The observations have been interpreted in the framework of the previously described coupled-chemistry-emission model, and the upper limits of the relative abundances of $\mathrm{CO}_{2}$ were derived from the observed $\mathrm{G} / \mathrm{R}$ ratios. Measuring the [OI] lines might provide a new way to determine the $\mathrm{CO}_{2}$ relative abundance in comets.
\end{abstract}

Key words. molecular processes - techniques: spectroscopic - line: formation - atomic processes - line: profiles - comets: general

\section{Introduction}

Comets are among the best-preserved specimens of the primitive solar nebula because the nucleus composition did not evolve much since their formation 4.6 billion years ago. Studying the composition of comet nuclei is thus essential to understand the formation and evolution of material within our solar system. Oxygen is one of the most abundant elements in comets since most of the cometary ices consist of $\mathrm{H}_{2} \mathrm{O}, \mathrm{CO}_{2}$, and $\mathrm{CO}$ molecules. All these molecules generated by the sublimation of cometary ices can produce oxygen atoms in the coma by photodissociation. Oxygen atoms in comets are analyzed through the three forbidden oxygen lines located at $5577.339 \AA$ for the green line, and at $6300.304 \AA$ and $6363.776 \AA$ for the red doublet. These emission lines are a result of the electronic transition of the oxygen atoms from the ${ }^{1} \mathrm{~S}$ state to the ${ }^{1} \mathrm{D}$ state (green line) and from the ${ }^{1} \mathrm{D}$ to the ground state (red doublet).

* Based on observations made with ESO Telescope at the La Silla Paranal Observatory under programs ID 073.C-0525, 277.C-5016, 080.C-0615 and 086.C-0958.

$\star \star$ Tables 3 and 4 are available in electronic form at http://www . aanda.org
In previous papers (Cochran 1984; Cochran \& Cochran 2001; Cochran 2008; Capria et al. 2010, and references therein), oxygen atoms were found to come mainly from the photodissociation of water molecules at a heliocentric distance of about $1 \mathrm{au}$. Decock et al. (2013) analyzed about 50 spectra belonging to 12 comets observed at $r \sim 1$ au and compared the theoretical ratio of the green-to-red-doublet emission intensity $(\mathrm{G} / \mathrm{R}$ ratio; see ${ }^{1} \mathrm{~S} /{ }^{1} \mathrm{D}$ in Table 1 ) with the observed ratios. This work confirmed that $\mathrm{H}_{2} \mathrm{O}$ is the main parent source of atomic oxygen in the cometary coma within a radial distance of $8000 \mathrm{~km}$ from the nucleus. The observation of these emission lines at larger heliocentric distances $(>2.5 \mathrm{au})$ has shown a higher $\mathrm{G} / \mathrm{R}$ ratio caused by significant $\mathrm{CO}_{2}$ contribution to the production of oxygen atoms (Decock et al. 2013). A similar higher $\mathrm{G} / \mathrm{R}$ ratio value on comets has also been observed by McKay et al. $(2012,2013)$. In the present paper, we study the three forbidden oxygen lines in the inner coma as closely as possible to the nucleus to determine the parent species that produce oxygen atoms at different nucleocentric distances. This analysis was made for four comets of different types (New, Jupiter family, Halley type) observed with the ESO Very Large Telescope with a good spatial resolution and high signal-to-noise ratio. We also study the effect of 
Table 1. Calculated $\mathrm{O}\left({ }^{1} \mathrm{~S}\right)$ and $\mathrm{O}\left({ }^{1} \mathrm{D}\right)$ photo rates and ${ }^{1} \mathrm{~S} /{ }^{1} \mathrm{D}$ ratios for the main oxygen-bearing species by Raghuram \& Bhardwaj (2013) for quiet-Sun condition and at $r \approx 1$ au.

\begin{tabular}{l|cc|c}
\hline \hline Parents & \multicolumn{2}{|c|}{ Emission rate $\left(\mathrm{s}^{-1}\right)$} & Ratio \\
& $\mathrm{O}\left({ }^{1} \mathrm{~S}\right)$ & $\mathrm{O}\left({ }^{1} \mathrm{D}\right)$ & ${ }^{1} \mathrm{~S} /{ }^{1} \mathrm{D}$ \\
\hline $\mathrm{H}_{2} \mathrm{O}$ & $3.78 \times 10^{-8}$ & $9.5 \times 10^{-7}$ & 0.040 \\
$\mathrm{CO}$ & $4.0 \times 10^{-8 a}$ & $6 \times 10^{-8}$ & 0.667 \\
$\mathrm{CO}_{2}$ & $8.5 \times 10^{-7}$ & $6.2 \times 10^{-7}$ & 1.371 \\
\hline
\end{tabular}

Notes. ${ }^{(a)}$ This rate comes from Huebner \& Carpenter (1979).

the collisional quenching of $\mathrm{O}\left({ }^{1} \mathrm{~S}\right)$ and $\mathrm{O}\left({ }^{1} \mathrm{D}\right)$ with the ambient cometary species (mainly water) on the $\mathrm{G} / \mathrm{R}$ ratio profile close to the nucleus $(\$ 1000 \mathrm{~km})$.

\section{Observations}

We carried out the observations on four comets, C/2002 T7 (LINEAR), 73P-C/Schwassmann-Wachmann 3, 8P/Tuttle, and 103P/Hartley 2 (hereafter C/2002 T7, 73P-C, 8P and 103P, respectively), using the high-resolution UVES spectrograph at ESO (VLT). The observations of comet C/2002 T7 have been made in May 2004 shortly after its perihelion (April 2004). In 1995, comet 73P/Schwassmann-Wachmann 3 was very active, and the nucleus split into several fragments (Böhnhardt et al. 1995). The oxygen emission lines have been observed on the brightest fragment, which is 73P-C. Spectra of comet $8 \mathrm{P}$ were obtained on three different nights during January and February 2008. The Jupiter family comet 103P/Hartley 2 was studied in great detail by the EPOXI NASA mission and many telescopes from September to November 2010 (A'Hearn et al. 2011; Meech et al. 2011). Our observations were scheduled at the Paranal Observatory during the EPOXI flyby period.

All the data correspond to spectroscopic observations made with the high-resolution UVES spectrograph mounted on the UT2 of the VLT (Manfroid et al. 2009; Jehin et al. 2009; Decock et al. 2013, and references therein). The peculiarity of these observations is that these comets were observed close to Earth, from 0.61 au for C/2002 T7 down to 0.15 au for 73P-C. These small geocentric distances provide a high spatial resolution (from 400 to $100 \mathrm{~km}$ per arc second) and permit us to analyze the coma species very closely to the nucleus. The complete sample consists of five spectra for $\mathrm{C} / 2002 \mathrm{~T} 7$, eight for 103P, three for $8 \mathrm{P}$, and one for $73 \mathrm{P}-\mathrm{C}$. The $0.4^{\prime \prime} \times 12^{\prime \prime}$ slit is usually centered on the nucleus. For C/2002 T7 and 103P, we also obtained spectra at offset positions, enabling us to study the [OI] lines at large distances from the nucleus. All the observing details and the offset values are given in Table 2 .

\section{Data reduction}

The extraction of the 1D spectra and the reduction procedure are described in Sect. 3 of Decock et al. (2013). To study the [OI] lines as closely as possible to the comet nucleus, we spatially extracted the spectra line by line. We divided the slit of each spectrum into different pixel zones corresponding to different distances to the nucleus. As shown in Fig. 1, various subslit zones are represented by different symbols and are also used in Figs. 3 to 6 . We obtained 14 spectra for comets C/2002 T7, 73P$\mathrm{C}$, and $103 \mathrm{P}$ along the 64 pixel slit, while for comet $8 \mathrm{P}$, five spectra were extracted for the 52 pixels slit length. For the spectra taken at large offset positions, we used the average value over

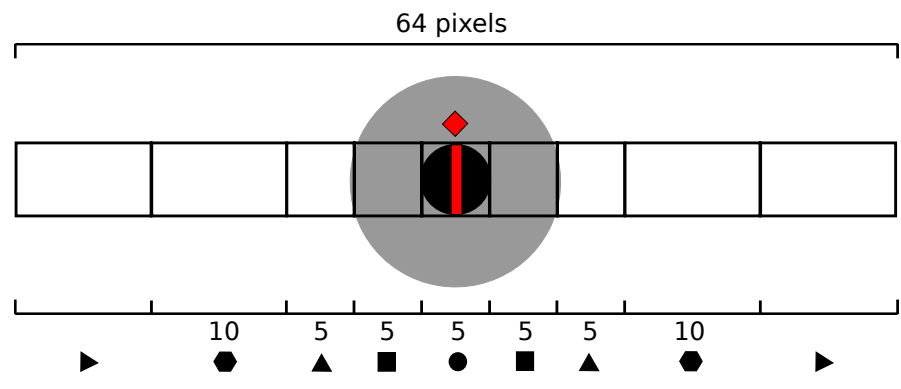

Fig. 1. Representation of the slit subdivision. Different symbols for different pixel zones are used in Figs. 3 to 6. The numbers given above the symbols correspond to the size of the subslit in pixels. The central pixel is represented by the red diamond symbol above the slit.

the whole slit to increase the signal-to-noise ratio, because in this case the change of distance from the nucleus is small within the slit.

\section{1. $C_{2}$ emission line subtraction}

Many $\mathrm{C}_{2}$ lines are located in the vicinity of the green line, and we have identified two of them at 5577.331 $\AA$ and 5577.401 that are blended with the oxygen line. The $\mathrm{C}_{2}$ contamination becomes stronger at large distances from the nucleus because the [OI] flux decreases faster than $\mathrm{C}_{2}$. This blend can affect both the flux and the width of the green line. To remove this contamination, we used another $\mathrm{C}_{2}$ line close to the oxygen line (the $\mathrm{P}_{3}(25)$ line of the $(1,2)$ Swan band at $5577.541 \AA)$ and created a synthetic $\mathrm{C}_{2}$ spectrum by fitting both the intensity and the profile of the lines. This synthetic spectrum was built using a Boltzmann distribution of the respective populations of the rotational levels with a temperature of $4000 \mathrm{~K}$. Because of the very close energy levels involved (same rotational number value for both the upper and lower vibronic states, see Rousselot et al. 2012, for more details of the Swan band structure) the exact rotational temperature value has very little influence on the final $C_{2}$ fit. The spectrum considered in our work is the spectrum observed after subtracting the $\mathrm{C}_{2}$ synthetic spectrum (see Fig. 2). This step was not necessary for 73P-C because there is no $\mathrm{C}_{2}$ feature detected around the green line. This comet is a $\mathrm{C}$-chain depleted comet (Schleicher et al. 2006) and thus very poor in $\mathrm{C}_{2}$.

\section{Results and discussion}

We used the software IRAF to measure the intensities and widths of the three [OI] lines by making a Gaussian fit.

\section{1. $G / R$ ratio}

When collisional quenching is neglected, the intensity $I$ of an emission line, expressed in Rayleighs ${ }^{1}(\mathrm{R})$, is given theoretically by Festou \& Feldman (1981),

$I=10^{-6} \tau_{\mathrm{p}}^{-1} \alpha \beta N$,

where $\tau_{\mathrm{p}}$ is the photodissociative lifetime of the parent species in seconds, $\alpha$ is the yield of photodissociation, $\beta$ corresponds to the branching ratio for the transition, and $N$ is the column density of the parent species in $\mathrm{cm}^{-2}$. The measured green and reddoublet emission intensities and the corresponding $G / R$ ratios for each spectrum of our observations are listed in Table 3 . The

$\overline{1 \mathrm{R}=10^{6} \text { photons } \mathrm{cm}^{-2} \mathrm{~s}^{-1}}$ in $4 \pi$ steradians. 
A. Decock et al.: [OI] lines in comets at various nucleocentric distances
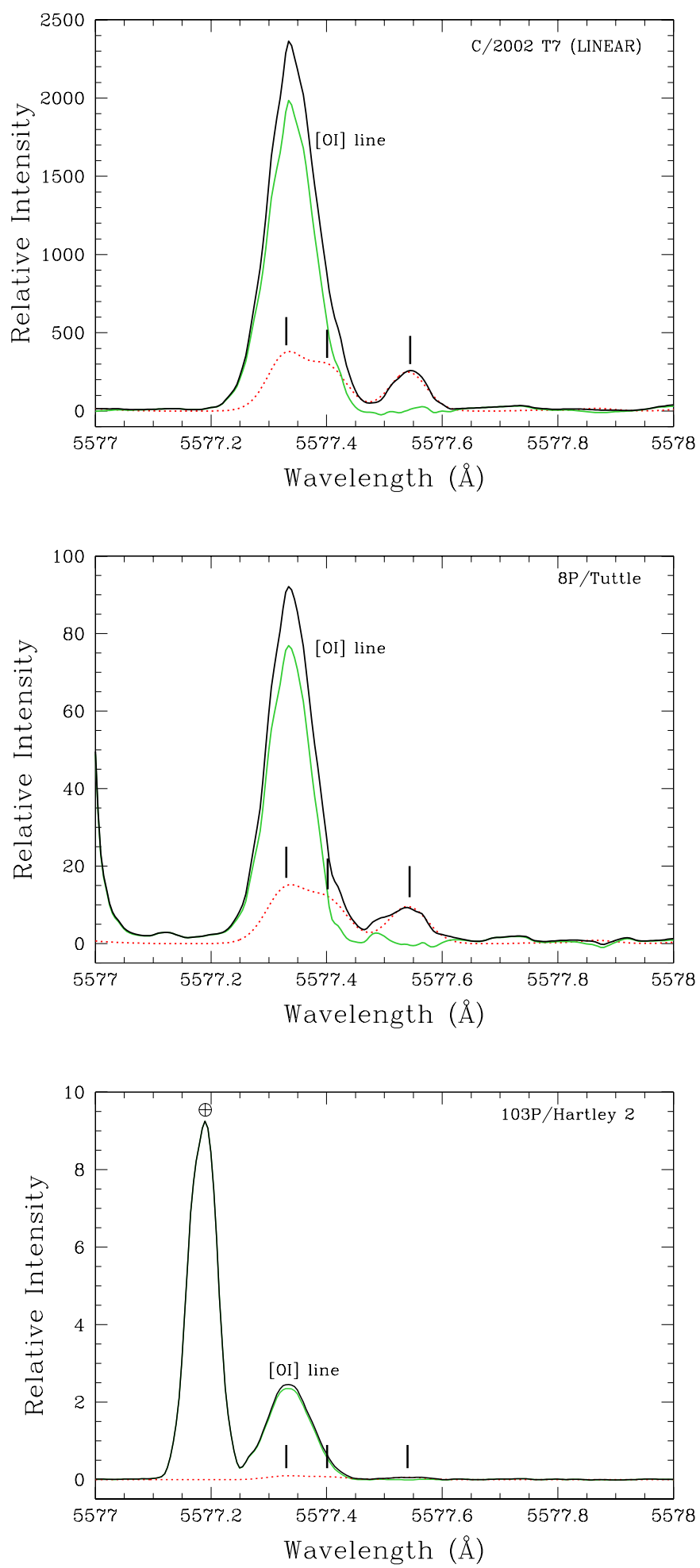

Fig. 2. Subtraction of $\mathrm{C}_{2}$ lines from the spectra of comets $\mathrm{C} / 2002 \mathrm{~T} 7$ (LINEAR), 8P/Tuttle and 103P/Hartley 2. The black spectrum shows the data not corrected for $\mathrm{C}_{2}$ while in the green one is after removing the $\mathrm{C}_{2}$ lines contamination. The $\mathrm{C}_{2}$ synthetic spectrum is represented by the dotted red line. The positions of $\mathrm{C}_{2}$ lines at 5577.331 $\AA, 5577.401 \AA$ and $5577.541 \AA$ are indicated with small vertical thick marks. The telluric [OI] line $(\oplus)$ is visible in the spectrum of comet 103P/Hartley 2.

$\mathrm{G} / \mathrm{R}$ ratio is displayed for the four comets with respect to the nucleus distance in Figs. 3-6. It is given in Table 4 with the errors on the $y$-axis estimated from the rms of the $\mathrm{N}$ spectra available

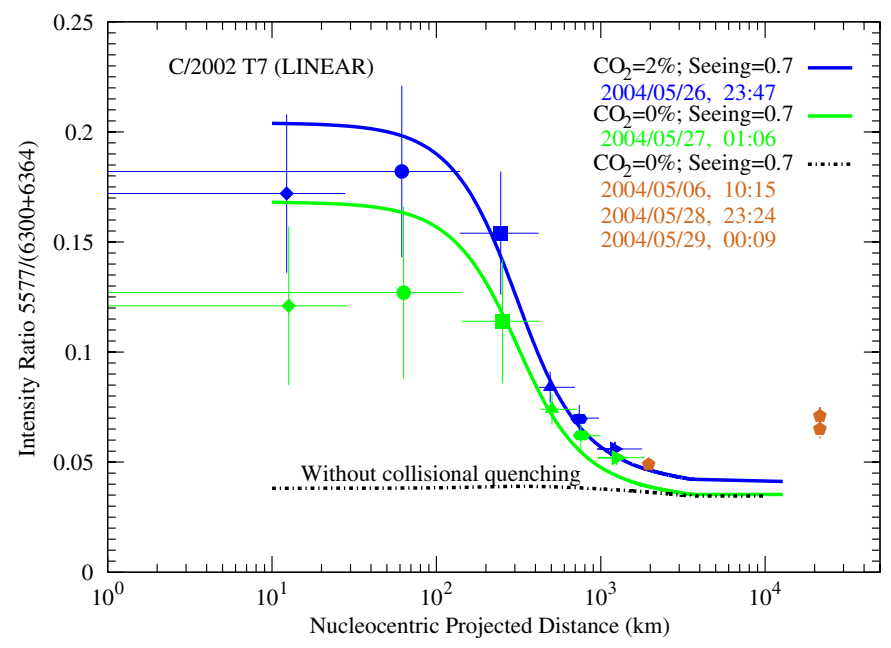

Fig. 3. G/R ratio for each subslit and offseted spectrum for comet C/2002 T7 (LINEAR). The range of the nucleocentric distances covered by each point and the error on the G/R ratio are represented. The seeing is included in the $x$-errors and is indicated in $\mathrm{km}$. It corresponds to the smallest size that can be resolved and explains the plateau found for the smallest spatial bin close to the nucleus. The $\mathrm{G} / \mathrm{R}$ ratios as a function of the projected nucleocentric distance are plotted with solid curves. An $\mathrm{H}_{2} \mathrm{O}$ production rate of $5.2 \times 10^{29} \mathrm{~s}^{-1}$ and a $5 \% \mathrm{CO}$ relative abundance were used with different seeing values and different $\mathrm{CO}_{2}$ relative abundances. The fits give the $\mathrm{CO}_{2}$ relative abundance of the comet. Only data points that were not offset were considered to computate the $\mathrm{G} / \mathrm{R}$ profile provided by the model. The black dash-dotted curve represents the calculated $\mathrm{G} / \mathrm{R}$ ratio not accounting for collisional quenching with $0 \% \mathrm{CO}_{2}$ relative abundance. The pentagon symbols are the data points for the offset observations.

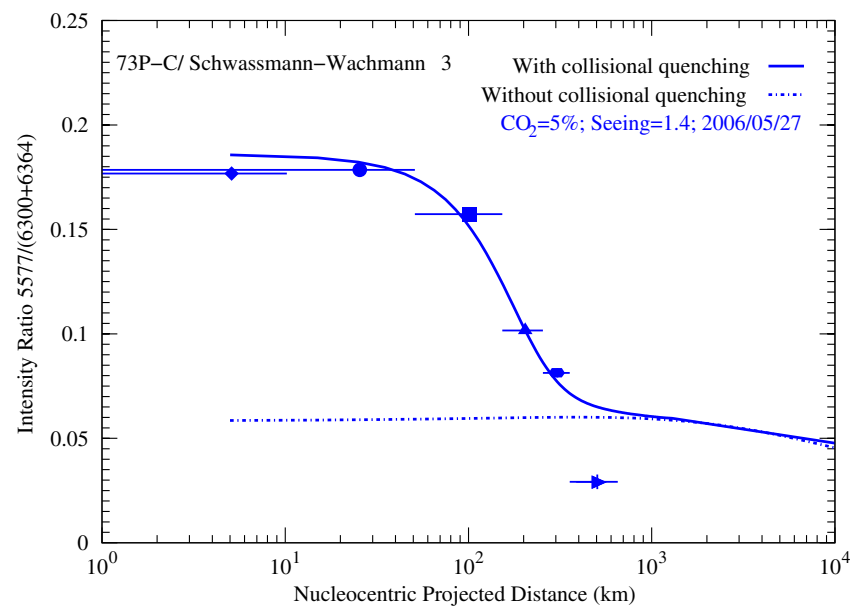

Fig. 4. G/R ratio for each subslit spectrum for comet 73P-C/ Schwassmann-Wachmann 3. The range of nucleocentric distances covered by each point is indicated. The model-calculated $\mathrm{G} / \mathrm{R}$ ratio as a function of projected distance is plotted with a solid curve. An $\mathrm{H}_{2} \mathrm{O}$ production rate of $1.7 \times 10^{28} \mathrm{~s}^{-1}$ and $0.5 \% \mathrm{CO}$ relative abundance were used. The fit gives the $\mathrm{CO}_{2}$ relative abundance of the comet. The blue dash-dotted curve represents the calculated $\mathrm{G} / \mathrm{R}$ ratio not accounting for collisional quenching with $0 \% \mathrm{CO}_{2}$ relative abundance.

for a given comet. Errors on the $x$-axis correspond to the spatial area (in $\mathrm{km}$ ) covered by the considered subslit. The atmospheric seeing limits the spatial resolution and defines the smallest nucleocentric distance that can be resolved. This smallest nucleocentric distance is provided in the last column of Table 2 and is also included in the $x$-axis errors. In Figs. $3-6$ the G/R ratio decreases monotonically with the projected distance from 
Table 2. Observational circumstances.

\begin{tabular}{|c|c|c|c|c|c|c|c|c|c|c|c|}
\hline Comet & UT date & $\begin{array}{c}r \\
(\mathrm{au})\end{array}$ & $\begin{array}{c}\dot{r} \\
\left(\mathrm{~km} \mathrm{~s}^{-1}\right) \\
\end{array}$ & $\begin{array}{c}\Delta \\
(\mathrm{au})\end{array}$ & $\begin{array}{c}\dot{\Delta} \\
\left(\mathrm{km} \mathrm{s}^{-1}\right) \\
\end{array}$ & $\begin{array}{l}\text { Exptime } \\
\text { (s) }\end{array}$ & $\begin{array}{c}\text { Offset } \\
\left({ }^{\prime \prime}\right)\end{array}$ & $\begin{array}{c}\text { Slit } \\
\left({ }^{\prime \prime} \times^{\prime \prime}\right)\end{array}$ & $\begin{array}{c}\text { Slit } \\
(\mathrm{km} \times \mathrm{km})\end{array}$ & $\begin{array}{l}\text { Seeing } \\
\left({ }^{\prime \prime}\right)\end{array}$ & $\begin{array}{r}\text { Seeing } \\
(\mathrm{km}) \\
\end{array}$ \\
\hline C/2002 T7 (LINEAR) & $2004 / 05 / 06,10: 15$ & 0.68 & 15.83 & 0.61 & -65.62 & 1080 & 5 & $0.44 \times 12.00$ & $195 \times 5309$ & 1.0 & 458 \\
\hline C/2002 T7 (LINEAR) & $2004 / 05 / 26,23: 47$ & 0.94 & 25.58 & 0.41 & 54.98 & 2678 & 0 & $0.30 \times 12.00$ & $89 \times 3568$ & 0.7 & 198 \\
\hline C/2002 T7 (LINEAR) & $2004 / 05 / 27,01: 06$ & 0.94 & 25.59 & 0.42 & 55.20 & 1800 & 0 & $0.30 \times 12.00$ & $91 \times 3655$ & 0.7 & 206 \\
\hline C/2002 T7 (LINEAR) & $2004 / 05 / 28,23: 24$ & 0.97 & 25.90 & 0.48 & 59.15 & 487 & 70 & $0.44 \times 12.00$ & $153 \times 4178$ & 1.0 & 354 \\
\hline C/2002 T7 (LINEAR) & $2004 / 05 / 29,00: 09$ & 0.97 & 25.90 & 0.48 & 59.26 & 3600 & 70 & $0.44 \times 12.00$ & $153 \times 4178$ & 1.0 & 205 \\
\hline 73P-C SW 3 & $2006 / 05 / 27,09: 28$ & 0.97 & -4.17 & 0.15 & 12.31 & 4800 & 0 & $0.60 \times 12.00$ & $65 \times 2611$ & 1.4 & 151 \\
\hline 8P/Tuttle & $2008 / 01 / 16,01: 00$ & 1.04 & -4.29 & 0.36 & 21.64 & 3600 & 0 & $0.44 \times 10.00$ & $115 \times 1305$ & 1.0 & 261 \\
\hline 8P/Tuttle & $2008 / 01 / 28,00: 58$ & 1.03 & 0.40 & 0.52 & 24.72 & 3900 & 0 & $0.44 \times 10.00$ & $166 \times 3771$ & 0.9 & 319 \\
\hline 8P/Tuttle & $2008 / 02 / 04,00: 57$ & 1.03 & 3.16 & 0.62 & 24.16 & 3900 & 0 & $0.44 \times 10.00$ & $198 \times 4497$ & 1.0 & 450 \\
\hline 103P/Hartley 2 & $2010 / 11 / 05,07: 18$ & 1.06 & 2.53 & 0.16 & 7.08 & 2900 & 0 & $0.44 \times 12.00$ & $51 \times 1393$ & 1.3 & 148 \\
\hline 103P/Hartley 2 & 2010/11/05, 08:19 & 1.06 & 2.55 & 0.16 & 7.19 & 3200 & 0 & $0.44 \times 12.00$ & $57 \times 1567$ & 1.8 & 205 \\
\hline 103P/Hartley 2 & 2010/11/10, 07:17 & 1.07 & 4.05 & 0.18 & 7.96 & 2900 & 0 & $0.44 \times 12.00$ & $57 \times 1567$ & 0.8 & 102 \\
\hline 103P/Hartley 2 & 2010/11/10, 08:19 & 1.07 & 4.07 & 0.18 & 8.07 & 3200 & 0 & $0.44 \times 12.00$ & $51 \times 1393$ & 0.8 & 97 \\
\hline 103P/Hartley 2 & $2010 / 11 / 11,05: 53$ & 1.08 & 4.33 & 0.19 & 7.94 & 4500 & 30 & $0.44 \times 12.00$ & $60 \times 1654$ & 0.6 & 76 \\
\hline 103P/Hartley 2 & 2010/11/11, 07:18 & 1.08 & 4.35 & 0.19 & 8.08 & 3600 & 20 & $0.44 \times 12.00$ & $60 \times 1654$ & 0.6 & 81 \\
\hline 103P/Hartley 2 & 2010/11/11, 08:16 & 1.08 & 4.36 & 0.19 & 8.19 & 2400 & 10 & $0.44 \times 12.00$ & $60 \times 1654$ & 0.6 & 82 \\
\hline 103P/Hartley 2 & $2010 / 11 / 11,08: 57$ & 1.08 & 4.37 & 0.19 & 8.27 & 900 & 0 & $0.44 \times 12.00$ & $60 \times 1654$ & 0.7 & 92 \\
\hline
\end{tabular}

Notes. $r$ is the heliocentric distance, $\Delta$ is the geocentric distance. $\dot{r}$ and $\dot{\Delta}$ are the heliocentric and geocentric velocities. Exptime corresponds to the exposure time in seconds. Offset (arc seconds) corresponds to the distance between the slit and the center of the cometary nucleus. The slit-tail orientation provides the direction of the slit with respect to the cometary tail. Slit is the size of the entrance slit of the spectrograph in arc seconds. The next column gives the projected area covered by the slit. The last two columns present the seeing values in arc seconds and in km during the observations.

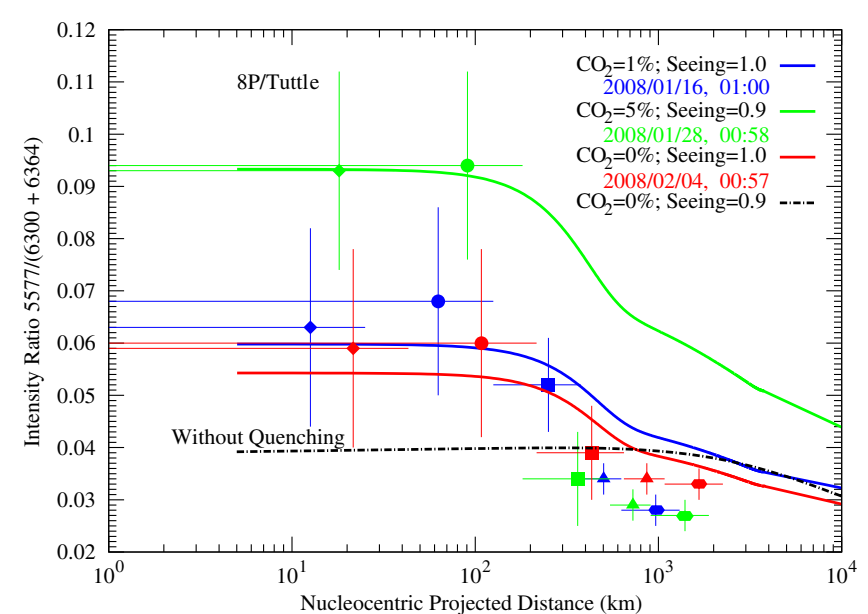

Fig. 5. G/R ratio for each subslit spectrum for comet $8 \mathrm{P} /$ Tuttle. The range of nucleocentric distances covered by each point and the error on the $\mathrm{G} / \mathrm{R}$ ratio are represented. The model-calculated $\mathrm{G} / \mathrm{R}$ ratios as a function of projected distance in the comet are plotted. $\mathrm{An}_{2} \mathrm{O}$ production rate of $1.4 \times 10^{28} \mathrm{~s}^{-1}$ and $0.5 \% \mathrm{CO}$ as relative abundance were used with different seeing values and different $\mathrm{CO}_{2}$ relative abundances. The fits give the $\mathrm{CO}_{2}$ relative abundance of the comet. The black dash-dotted curve represents the calculated $\mathrm{G} / \mathrm{R}$ ratio not accounting for collisional quenching with $0 \% \mathrm{CO}_{2}$ relative abundance.

the nucleus. This is due to strong collisional quenching of the excited oxygen atoms by $\mathrm{H}_{2} \mathrm{O}$ (Bhardwaj \& Raghuram 2012). Since the lifetime of $\mathrm{O}\left({ }^{1} \mathrm{D}\right)$ atoms is $\sim 100$ times longer than the lifetime of $\mathrm{O}\left({ }^{1} \mathrm{~S}\right)$, the $\mathrm{O}\left({ }^{1} \mathrm{D}\right)$ is destroyed more frequently by quenching (Raghuram \& Bhardwaj 2014), which implies an increase of the $G / R$ ratio close to the nucleus. This is what we see in our observations. Without accounting for collisional quenching of $\mathrm{O}\left({ }^{1} \mathrm{~S}\right)$ and $\mathrm{O}\left({ }^{1} \mathrm{D}\right)$, the model-calculated $\mathrm{G} / \mathrm{R}$ ratio profiles are plotted with dash-dotted curves in Figs. 3 to 6. The $\mathrm{G} / \mathrm{R}$ ratio is almost flat throughout the projected coma of all these comets and is significantly loweer than the observed

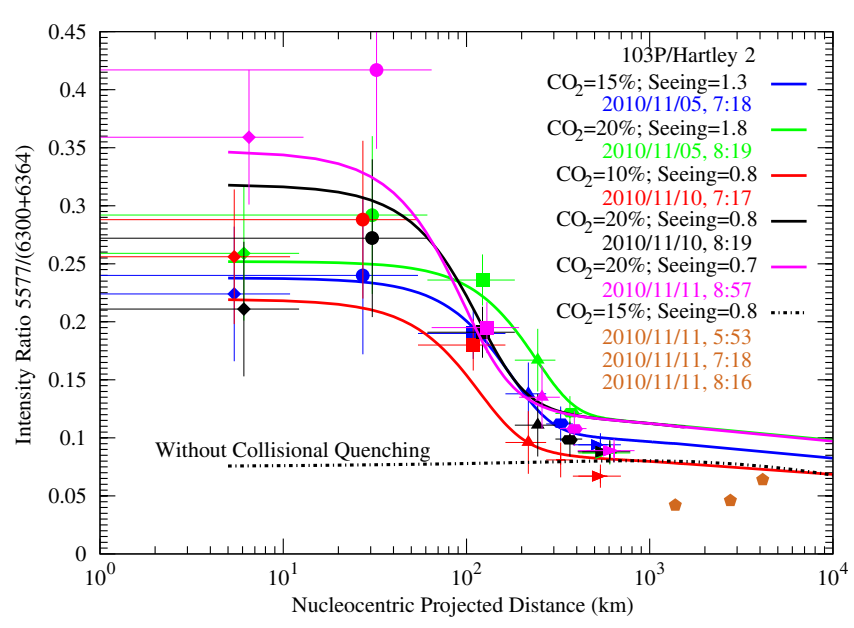

Fig. 6. G/R ratio for each subslit and offset spectrum for comet 103P/Hartley 2. The range of nucleocentric distances covered by each point and the error on the $\mathrm{G} / \mathrm{R}$ ratio are represented. The modelcalculated $\mathrm{G} / \mathrm{R}$ ratios as a function of projected distance are plotted. An $\mathrm{H}_{2} \mathrm{O}$ production rate of $1.18 \times 10^{28} \mathrm{~s}^{-1}$ and $0.5 \% \mathrm{CO}$ as relative abundance were used with different seeing values and different $\mathrm{CO}_{2}$ relative abundances. The fits give the $\mathrm{CO}_{2}$ relative abundance of the comet. The black dash-dotted curve represents the calculated $\mathrm{G} / \mathrm{R}$ ratio not accounting for collisional quenching with $15 \% \mathrm{CO}_{2}$ relative abundance. The pentagon symbols are the data points for the offset observations.

values very close to the nucleus. This calculation shows how important collisional quenching is in determining the G/R ratio in comets. The destruction rate profiles of $\mathrm{O}\left({ }^{1} \mathrm{~S}\right)$ and $\mathrm{O}\left({ }^{1} \mathrm{D}\right)$ by $\mathrm{H}_{2} \mathrm{O}$ in the innermost coma depend on the size of the collisional coma of the comet, which is proportional to the water production rate. The higher the $\mathrm{H}_{2} \mathrm{O}$ production rate, the more extended the collisional coma and the stronger the quenching by $\mathrm{H}_{2} \mathrm{O}$ molecules. That is why comet $\mathrm{C} / 2002 \mathrm{~T} 7$ (LINEAR), with a higher $Q_{\mathrm{H}_{2} \mathrm{O}} \sim 5 \times 10^{29} \mathrm{~s}^{-1}$, reaches the lowest $\mathrm{G} / \mathrm{R}$ ratio at larger distances $(\sim 1000 \mathrm{~km})$ than the other comets $(\sim 500 \mathrm{~km})$. 
A. Decock et al.: [OI] lines in comets at various nucleocentric distances

Table 5. Water production rates around the observing dates. Comets Hyakutake and Hale-Bopp are included for comparison.

\begin{tabular}{lcccr}
\hline \hline Comet & $r$ & $Q_{\mathrm{H}_{2} \mathrm{O}}\left(10^{28} \mathrm{~s}^{-1}\right)$ & Date & Reference for $Q_{\mathrm{H}_{2} \mathrm{O}}$ \\
\hline C/2002 T7 (LINEAR) & 0.68 & 35.5 & 2004 May 5 & DiSanti et al. (2006) \\
& 0.94 & 52.1 & 2004 May 27 & Combi et al. (2009) \\
73P-C/Schwassmann-Wachmann 3 & 0.95 & 1.70 & 2006 May 17 & Schleicher \& Bair (2011) \\
8P/Tuttle & 1.04 & 1.4 & 2008 Jan. 3 & Barber et al. (2009) \\
103P/Hartley 2 & 1.06 & 1.15 & 2010 Nov. 31 & Knight \& Schleicher (2013) \\
C/1996 B2 (Hyakutake) & 0.94 & 26 & 1996 Apr. 1 & Combi et al. (1998) \\
C/1995 A1 (Hale-Bopp) & 0.93 & 957 & 1997 Mar 26 & Dello Russo et al. (2000) \\
\hline
\end{tabular}

Table 6. Input parameters used in the model and the derived $\mathrm{CO}_{2}$ abundances relative to $\mathrm{H}_{2} \mathrm{O}$.

\begin{tabular}{lcccc}
\hline \hline Comet & $\begin{array}{c}Q_{\mathrm{H}_{2} \mathrm{O}^{a}} \\
\left(10^{28} \mathrm{~s}^{-1}\right)\end{array}$ & $\begin{array}{c}r \\
(\mathrm{au})\end{array}$ & \multicolumn{2}{c}{ Relative abundance (\%) } \\
{$[\mathrm{CO}]$} & Model $\left[\mathrm{CO}_{2}\right]$ \\
\hline C/2002 T7 (LINEAR) & 52 & 0.94 & $5^{b}$ & $0-2$ \\
73P-C/Schwassmann-Wachmann 3 & 1.7 & 0.95 & $5^{b}$ & 5 \\
8P/Tuttle & 1.4 & 1.03 & $0.5^{c}$ & $0-5$ \\
103P/Hartley 2 & 1.15 & 1.06 & $0.15-0.45^{d}$ & $15-20$ \\
\hline
\end{tabular}

Notes. ${ }^{(a)}$ Taken from Table 5. ${ }^{(b)}$ Assumed by the model of Raghuram \& Bhardwaj. ${ }^{(c)}$ Bonev et al. (2008). ${ }^{(d)}$ Weaver et al. (2011).

We also analyzed the theoretical estimates of production rates for $\mathrm{O}\left({ }^{1} \mathrm{~S}\right)$ and $\mathrm{O}\left({ }^{1} \mathrm{D}\right)$ atoms, which depend on the water production rate (Raghuram \& Bhardwaj 2013, 2014). For comets 73P-C, 8P, and $103 \mathrm{P}$ with $Q_{\mathrm{H}_{2} \mathrm{O}} \sim 10^{28} \mathrm{~s}^{-1}, \mathrm{O}\left({ }^{1} \mathrm{~S}\right)$ comes from both $\mathrm{CO}_{2}$ and $\mathrm{H}_{2} \mathrm{O}$, while $\mathrm{O}\left({ }^{1} \mathrm{D}\right)$ is only produced by the photodissociation of $\mathrm{H}_{2} \mathrm{O}$. However, for $\mathrm{C} / 2002 \mathrm{~T} 7$ (LINEAR) the $\mathrm{O}\left({ }^{1} \mathrm{~S}\right)$ atoms are formed by the photodissociation of $\mathrm{CO}_{2}$ close to the nucleus $(<50 \mathrm{~km})$ and, beyond, by both $\mathrm{CO}_{2}$ and $\mathrm{H}_{2} \mathrm{O}$. Therefore, the $\mathrm{O}\left({ }^{1} \mathrm{~S}\right) / \mathrm{O}\left({ }^{1} \mathrm{D}\right)$ values in Table 1 should report a higher $\mathrm{G} / \mathrm{R}$ ratio below $50 \mathrm{~km}$ for this comet. Unfortunately, the atmospheric seeing does not permit us to resolve the coma at such small distances to the nucleus. Beyond $10^{3} \mathrm{~km}$, the main contribution to both $\mathrm{O}\left({ }^{1} \mathrm{~S}\right)$ and $\mathrm{O}\left({ }^{1} \mathrm{D}\right)$ is the photodissociation of $\mathrm{H}_{2} \mathrm{O}$ molecules. As shown in Figs. 3-6, at these distances the $\mathrm{G} / \mathrm{R}$ ratio reaches a constant value of $\sim 0.05$, which is very similar to the $\mathrm{O}\left({ }^{1} \mathrm{~S}\right) / \mathrm{O}\left({ }^{1} \mathrm{D}\right)$ value for the pure water case (cf. Table 1$)$.

\subsubsection{Estimation of $\mathrm{CO}_{2}$ relative abundances}

We used the coupled-chemistry-emission model of Bhardwaj \& Raghuram (2012) to estimate the $\mathrm{CO}_{2}$ relative abundance (i.e., the $\mathrm{CO}_{2} / \mathrm{H}_{2} \mathrm{O}$ abundance ratio) in these comets by comparing the observed slit-centered G/R data points. The model accounts for the main production and loss processes of $\mathrm{O}\left({ }^{1} \mathrm{~S}\right)$ and $\mathrm{O}\left({ }^{1} \mathrm{D}\right)$ atoms in the inner cometary coma. It also includes the collisional quenching of $\mathrm{O}\left({ }^{1} \mathrm{~S}\right)\left(4 \times 10^{-10}\right.$ molecule ${ }^{-1} \mathrm{~cm}^{3} \mathrm{~s}^{-1}$, Stuhl \& Welge 1969) and $\mathrm{O}\left({ }^{1} \mathrm{D}\right)\left(2.1 \times 10^{-10}\right.$ molecule $^{-1} \mathrm{~cm}^{3} \mathrm{~s}^{-1}$, Atkinson et al. 2004; Takahashi et al. 2005) by $\mathrm{H}_{2} \mathrm{O}$ in the inner coma. More details about the model calculations are given in Bhardwaj \& Raghuram (2012) and Raghuram \& Bhardwaj (2013, 2014). We took the atmospheric seeing effect into account, which is especially strong very close to the nucleus. For this, we convolved the spatial profile provided by the model with a Gaussian of FWHM equal to the seeing value. The seeing values were obtained from the Paranal seeing monitor. The $\mathrm{H}_{2} \mathrm{O}$ production rates and the seeing values used in the model as well as the corresponding heliocentric distances are given in Tables 2 and 5. The CO relative abundances for comets C/2002 T7 and $73 \mathrm{P}-\mathrm{C}$ are assumed to be equal to $5 \%$ in the model. However, earlier works (Bhardwaj \& Haider 2002; Raghuram \& Bhardwaj 2013,2014 ) have shown that the role of CO in the determining $\mathrm{G} / \mathrm{R}$ ratio is insignificant. The derived $\mathrm{CO}_{2}$ relative abundances obtained by fitting the observed G/R profiles with the model are provided in the last column of Table 6 .

The comparison between the observed and computed G/R profiles of comet $\mathrm{C} / 2002 \mathrm{~T} 7$ shown in Fig. 3 indicates that the relative abundance of $\mathrm{CO}_{2}$ in this comet is lower than $2 \%$. The computed $\mathrm{G} / \mathrm{R}$ profile for comet $73 \mathrm{P}-\mathrm{C}$ with $5 \% \mathrm{CO}_{2}$ relative abundance is presented in Fig. 4 together with the observations. The model calculations for comet $8 \mathrm{P}$ suggest that for $8 \mathrm{P} /$ Tuttle, the $\mathrm{CO}_{2}$ relative abundance probably is between 0 and $5 \%$. In comet 103P (shown in Fig. 6), the required $\mathrm{CO}_{2}$ relative abundances necessary to reproduce the observations are about 15 to $20 \%$, which agrees with the $\mathrm{CO}_{2}$ measurements obtained by EPOXI observations (A'Hearn et al. 2011). This is the only comet with such a high $\mathrm{CO}_{2}$ abundance in our sample. The observed data close to the nucleus are very well fitted with the model calculations for all these comets, which indicates that the $\mathrm{O}\left({ }^{1} \mathrm{~S}\right)$ and $\mathrm{O}\left({ }^{1} \mathrm{D}\right)$ collisional quenching rates measured by Stuhl \& Welge (1969) and Takahashi et al. (2005) lie in a plausible range.

\subsubsection{P/Hartley 2}

Two data points very close to the nucleus (observed on 2010/11/11, 8:57) appear to be relatively high in Fig. 6, while the other points farther away from the nucleus have $G / R$ values similar to those of the other spectra. First, we considered a possible contamination by a cosmic rays, but an analysis of the three [OI] lines in the 2D spectra shows no cosmic-ray event (see Fig. 7). Figure 7 also confirms that there was no problem during the acquisition of this spectrum by comparing it with the spectrum taken the day before. This suggests that the $\mathrm{CO}_{2} / \mathrm{H}_{2} \mathrm{O}$ abundance sometimes strongly varies close to the nucleus. These variations might be generated by icy particles that evaporate very fast in the first ten kilometers and/or by the rotation of the nucleus, because it has been shown that the $\mathrm{CO}_{2}$ comes from a localized region (the small lobe) of the nucleus (A'Hearn et al. 2011).

\subsection{Line widths}

Using relation (9) given in Decock et al. (2013),

$F W H M(v)=\frac{F W H M_{\text {intrinsic }}(\lambda) c}{2 \lambda_{[\mathrm{OI}]} \sqrt{\ln 2}}$, 

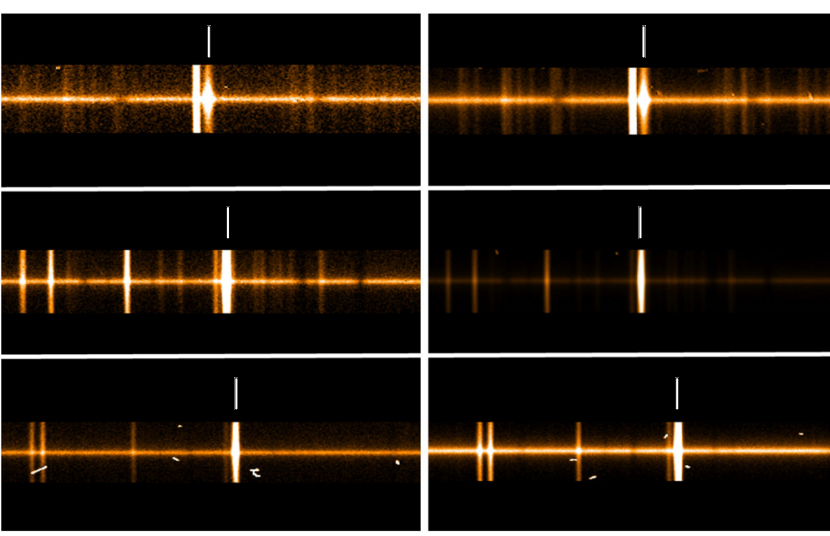

Fig. 7. [OI] lines in $2 \mathrm{D}$ echelle spectra of $103 \mathrm{P} /$ Hartley 2 , on 2010/11/10, 09:19 (right) and on 2010/11/11, 08:57 (left). From top to bottom, the $5577 \AA, 6300 \AA$ and $6364 \AA$ lines. The positions of the [OI] lines are indicated. No cosmic-ray feature contaminates the [OI] lines.

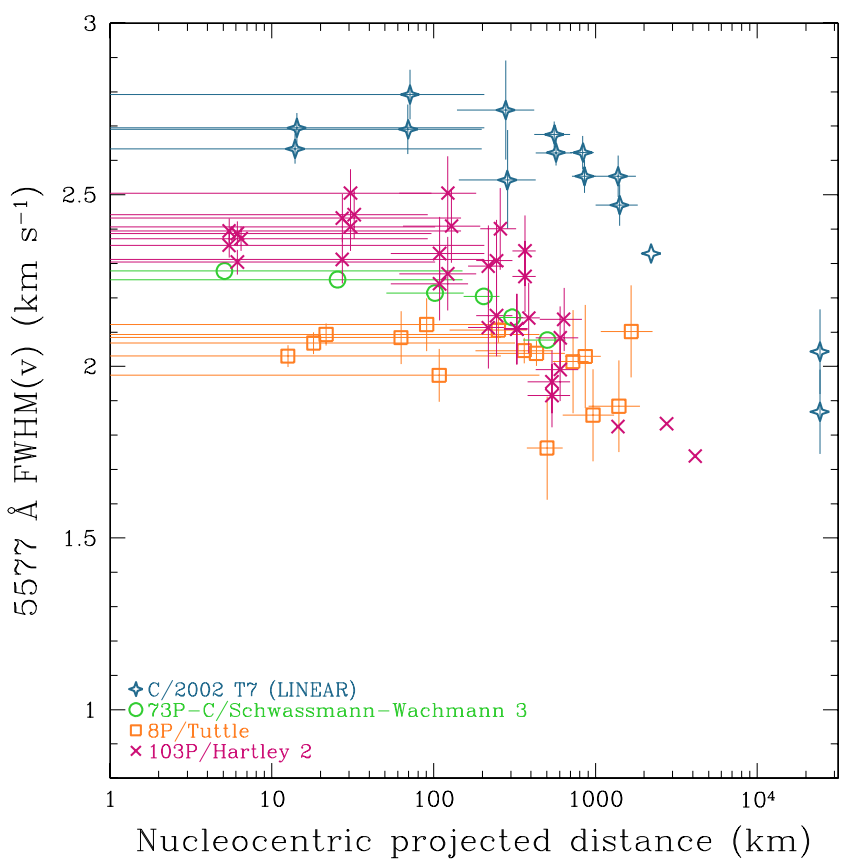

Fig. 8. $5577.339 \AA$ line width against the distance to the nucleus for all comets. The errors on the distance and widths are represented. A decreasing width with nucleocentric distance is observed for all comets. Within about $300 \mathrm{~km}$, there is a plateau because of the convolution by the seeing.

the intrinsic line widths $(\operatorname{FWHM}(\lambda))$ corrected for the instrumental broadening are evaluated from the measured FWHM $_{\text {observed }}(\AA)$. The results are listed in Table 3, the errors on the velocity widths are provided in Table 4. Figures 8-10 plot the intrinsic width of the three forbidden oxygen lines as a function of the nucleocentric distance. Our observations clearly show that the green line is wider than the red lines $\left(\sim 2.5 \mathrm{~km} \mathrm{~s}^{-1}\right.$ versus $\sim 1.5 \mathrm{~km} \mathrm{~s}^{-1}$ ) even after the subtracting the $C_{2}$ contamination. This was first reported by Cochran (2008) and confirmed by Decock et al. (2013) for a large sample of comets. We emphasize that 73P-C presents, like all comets, a wider green line, but is very poor in $C_{2}$. Therefore, the greater width of the $5577 \AA$ line cannot be explained by the $\mathrm{C}_{2}$ blends alone. A blend with another species cannot be excluded, but is unlikely. The width of the green line decreases when the distance to the nucleus

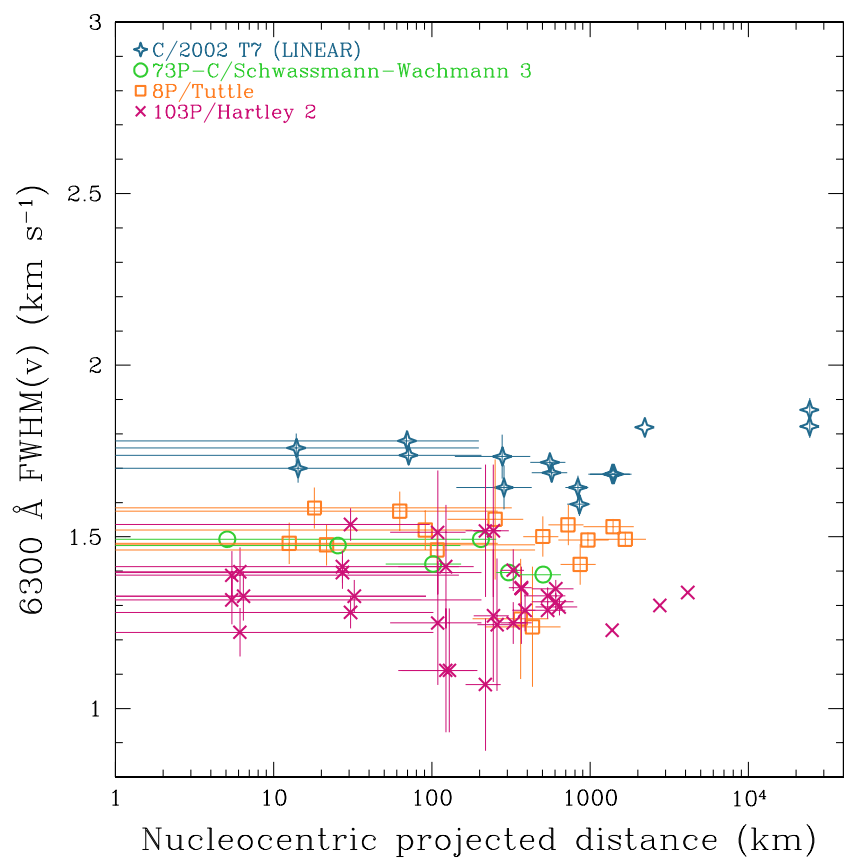

Fig. 9. Same as Fig. 8, but for the 6300.304 Å line.

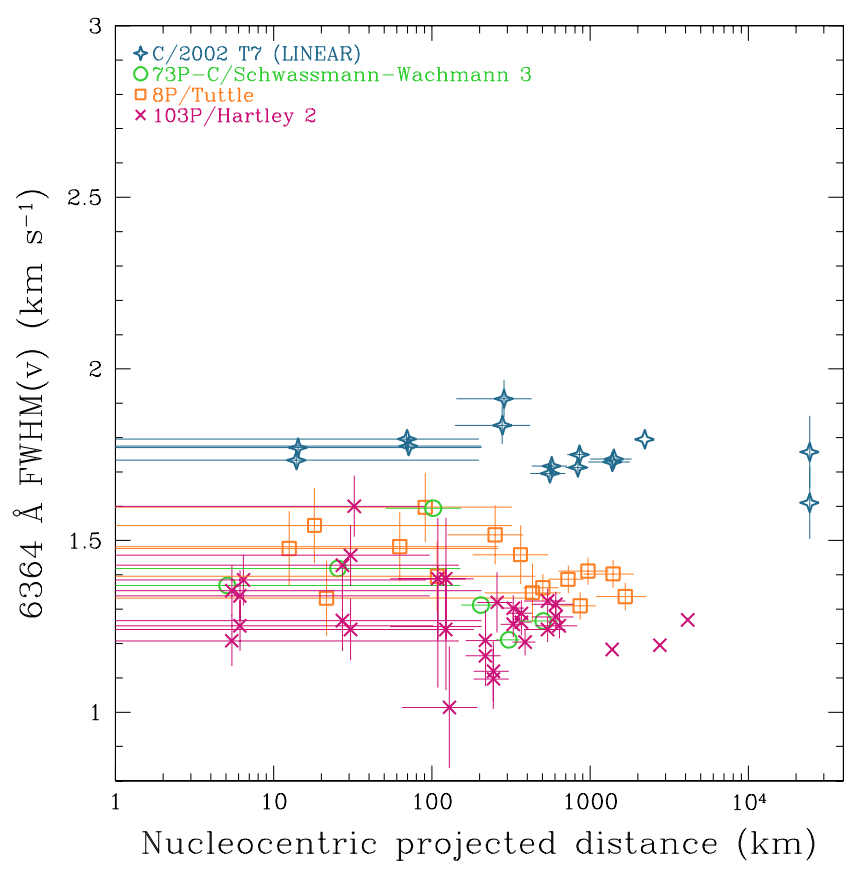

Fig. 10. Same as Fig. 8, but for the $6363.776 \AA$ A line.

increases (Fig. 8). This trend is more obvious for comets $\mathrm{C} / 2002$ $\mathrm{T} 7$ and 103P, for which we have spectra taken at large distances from the nucleus. The width of the green line at large distance also becomes similar to the width of the red lines. From extrapolating the linear regression for the width of the green line of $103 \mathrm{P}$ and C/2002 T7 with distance, we expect that the width of the green line will become equal to width of the red line at $\sim 5000 \mathrm{~km}$ for $103 \mathrm{P}$ and at $\sim 35000 \mathrm{~km}$ for $\mathrm{C} / 2002 \mathrm{~T} 7$. More observations at larger distances from the nucleus are necessary to confirm this. We cannot explain this behavior by the collisional quenching because this is not observed for the red lines. Indeed, as already mentioned by Raghuram \& Bhardwaj (2014), the $\mathrm{O}\left({ }^{1} \mathrm{D}\right)$ atoms are more quenched than the $\mathrm{O}\left({ }^{1} \mathrm{~S}\right)$ atoms because of their longer 
lifetimes. Therefore, the collisional quenching should make the red line wider than the green line, which is not observed. The greater width of the green line close to the nucleus might arise because the $\mathrm{O}\left({ }^{1} \mathrm{~S}\right)$ atoms are mainly produced by $\mathrm{CO}_{2}$ very close to the nucleus. Indeed, the solar flux responsible for the production of $\mathrm{O}\left({ }^{1} \mathrm{~S}\right)$ from $\mathrm{CO}_{2}$ comes from the 955-1165 $\AA$ region (Bhardwaj \& Raghuram 2012), which is more energetic than the Lyman- $\alpha$ photons, which are considered to be the main source of oxygen-atom production from $\mathrm{H}_{2} \mathrm{O}$ dissociation. These energetic photons can penetrate the thick coma more deeply than the Lyman- $\alpha$ photons. Since the line width is related to the value of the excess energy after the photodissociation, an excitation by higher energetic photons produces greater widths, as is observed for the green line close to the nucleus. The excess energy of different parent molecules has been evaluated by Raghuram \& Bhardwaj (2014). They found that the excess energy from $\mathrm{CO}_{2}$ is higher than that from $\mathrm{H}_{2} \mathrm{O}$. When the $\mathrm{O}\left({ }^{1} \mathrm{~S}\right)$ atoms are observed far away from the nucleus, they come from both $\mathrm{CO}_{2}$ and $\mathrm{H}_{2} \mathrm{O}$, but with Lyman- $\alpha$ photons as the main excitation source, followed by a stronger contribution from the water molecules, which results in a decreasing width of the green line.

Bisikalo et al. (2014) investigated the greater width of the green line and provided a different explanation. They developed a Monte Carlo model to study the [OI] line widths and suggested that the observed line profile also depends on the thermalization by elastic collisions. However, the thermalization process leads to a broadening of the red lines, not of the green line, which disagrees with our observations.

Figures 8 to 10 show that the widths of the three forbidden oxygen lines of C/2002 T7 (LINEAR) are always greater than the widths of the other comets. We explain this by the higher water production rate of this comet. Tseng et al. (2007) have shown that the expansion velocity of the molecules increases when the water production rate increases.

\section{Conclusions}

Four comets were observed at small geocentric distances with the UVES spectrograph (VLT). Seventeen high-resolution spectra were collected when the comets were very close to Earth $(<0.65 \mathrm{au})$, allowing us to study the [OI] lines as closely as $100 \mathrm{~km}$ to the nucleus. Some of them were also recorded with an offset from the nucleus corresponding to a distance of $10000 \mathrm{~km}$. The 11 centered spectra were spatially extracted and binned per pixel zones to obtain 1D spectra at various distances from the nucleus. Finally, we studied the forbidden oxygen lines in 63 sub-spectra and 6 offset spectra corresponding to different nucleocentric distances. The $\mathrm{G} / \mathrm{R}$ ratio and the velocity widths were computed and analyzed to better understand the production of oxygen atoms in the coma. The results can be summarized as follows:

1. In this analysis, $\mathrm{C}_{2}$ blends were identified and removed from the oxygen green line. This subtraction, made for the first time, is important because this contamination modifies the intensity and the FWHM of the $5577.339 \AA$ line for comets rich in $\mathrm{C}_{2}$ and more specifically for the analysis made far away from the nucleus ${ }^{2}$. However, the $\mathrm{C}_{2}$ blends do not explain the greater width of the green line compared with the width of the red lines.

\footnotetext{
2 Note that the $\mathrm{C}_{2}$ correction has no influence on our previous results (Decock et al. 2013).
}

2. Thanks to the high spatial resolution of the data, we found that the $G / R$ ratio as a function of the nucleocentric distance displays the same profile for all the comets: a rapid increase below $1000 \mathrm{~km}$ up to typically 0.2 , and a constant value of about 0.05 at larger distances. The $G / R$ value of about 0.1 found in previous studies is thus an average of the values obtained both close to the nucleus and at larger distances. This particular profile is mainly explained by the quenching, which plays an important role in the destruction of $\mathrm{O}\left({ }^{1} \mathrm{D}\right)$ atoms in the inner coma $(<1000 \mathrm{~km})$. The parent molecules forming oxygen atoms can also contribute to this trend. Indeed, $\mathrm{O}\left({ }^{1} \mathrm{D}\right)$ atoms are only formed by $\mathrm{H}_{2} \mathrm{O}$, while $\mathrm{O}\left({ }^{1} \mathrm{~S}\right)$ are produced by both $\mathrm{CO}_{2}$ and $\mathrm{H}_{2} \mathrm{O}$. With increasing distance from the nucleus, the relative $\mathrm{H}_{2} \mathrm{O}$ contribution becomes stronger and thus the intensity of the green line decreases. In the extended coma, oxygen atoms are only formed by the photodissociation of water molecules. The $\mathrm{G} / \mathrm{R}$ value of 0.05 agrees well with the pure water case (Table 1).

3. We fitted our observational $[\mathrm{OI}]$ emission lines data with coupled-chemistry-emission model calculations. The comparison between observations and model calculations indicates that the collisional quenching of $\mathrm{O}\left({ }^{1} \mathrm{~S}\right)$ and $\mathrm{O}\left({ }^{1} \mathrm{D}\right)$ by $\mathrm{H}_{2} \mathrm{O}$ molecules is significant in the inner coma and cannot be neglected when the $\mathrm{G} / \mathrm{R}$ ratio is determined. With the measured $G / R$ values close to the nucleus, an estimate of the relative abundance of $\mathrm{CO}_{2}$ was also derived for all the comets of the sample.

4. The green line has a much greater width, typically $2.5 \mathrm{~km} \mathrm{~s}^{-1}$ , compared with the $1.5 \mathrm{~km} \mathrm{~s}^{-1}$ found for the red lines. The greater width of the green line is most likely a result of the involvement of different parent molecules in producing the $\mathrm{O}\left({ }^{1} \mathrm{~S}\right)$ and $\mathrm{O}\left({ }^{1} \mathrm{D}\right)$ atoms (as already suggested by Bhardwaj \& Raghuram 2012; Decock et al. 2013): the green oxygen lines are produced by oxygen atoms coming from the photodissociation of both the $\mathrm{CO}_{2}$ and $\mathrm{H}_{2} \mathrm{O}$ molecules, while the red lines are mainly produced by $\mathrm{H}_{2} \mathrm{O}$ molecules. While the $\mathrm{O}\left({ }^{1} \mathrm{~S}\right)$ atoms are mostly provided by $\mathrm{CO}_{2}$, the contribution of water molecules increases with the nucleocentic distance. This explains the decreasing width of the $5577.339 \AA$ line at distances larger than $500 \mathrm{~km}$.

5. Measuring the green and red-doublet emission intensities and their line widths is a new way to constrain the $\mathrm{CO}_{2}$ relative abundances in comets.

Acknowledgements. A.D. acknowledges the support of the Belgian National Science Foundation F.R.I.A., Fonds pour la formation à la Recherche dans l'Industrie et l'Agriculture. S.R. was supported by ISRO Research associateship during a part of this work. The work of A.B. was supported by ISRO. C. Arpigny is thanked for helpful discussions and important constructive comments. S.R. acknowledges the support of the Science and Technology Facilities Council (STFC) through the Consolidated Grant to Imperial College London.

\section{References}

A'Hearn, M. F., Belton, M. J. S., Delamere, W. A., et al. 2011, Science, 332, 1396

Atkinson, R., Baulch, D. L., Cox, R. A., et al. 2004, Atmos. Chem. Phys., 4, 1461

Barber, R. J., Miller, S., Dello Russo, N., et al. 2009, MNRAS, 398, 1593

Bhardwaj, A., \& Haider, S. A. 2002, Adv. Space Res., 29, 745

Bhardwaj, A., \& Raghuram, S. 2012, ApJ, 748, 13

Bisikalo, D. V., Shematovich, V. I., Gerard, J.-C., et al. 2014, ApJ, accepted

Böhnhardt, H., Kaufl, H. U., Keen, R., et al. 1995, IAU Circ., 6274, 1

Bonev, B. P., Mumma, M. J., Radeva, Y. L., et al. 2008, ApJ, 680, L61

Capria, M. T., Cremonese, G., \& de Sanctis, M. C. 2010, A\&A, 522, A82

Cochran, A. L. 2008, Icarus, 198, 181 
A\&A 573, A1 (2015)

Cochran, W. D. 1984, Icarus, 58, 440

Cochran, A. L., \& Cochran, W. D. 2001, Icarus, 154, 381

Combi, M. R., Brown, M. E., Feldman, P. D., et al. 1998, ApJ, 494, 816

Combi, M. R., Mäkinen, J. T. T., Bertaux, J.-L., Lee, Y., \& Quémerais, E. 2009, AJ, 137, 4734

Decock, A., Jehin, E., Hutsemékers, D., \& Manfroid, J. 2013, A\&A, 555, A34

Dello Russo, N., Mumma, M. J., DiSanti, M. A., et al. 2000, Icarus, 143, 324

DiSanti, M. A., Bonev, B. P., Magee-Sauer, K., et al. 2006, ApJ, 650, 470

Festou, M., \& Feldman, P. D. 1981, A\&A, 103, 154

Huebner, W. F., \& Carpenter, C. W. 1979, NASA STI/Recon Technical Report N, 80,24243

Jehin, E., Manfroid, J., Hutsemékers, D., Arpigny, C., \& Zucconi, J.-M. 2009, Earth Moon and Planets, 105, 167

Knight, M. M., \& Schleicher, D. G. 2013, Icarus, 222, 691

Manfroid, J., Jehin, E., Hutsemékers, D., et al. 2009, A\&A, 503, 613

McKay, A. J., Chanover, N. J., DiSanti, M. A., et al. 2012, LPI Contributions, 1667,6212
McKay, A. J., Chanover, N. J., Morgenthaler, J. P., et al. 2013, Icarus, 222, 684

Meech, K. J., A'Hearn, M. F., Adams, J. A., et al. 2011, ApJ, 734, L1

Raghuram, S., \& Bhardwaj, A. 2013, Icarus, 223, 91

Raghuram, S., \& Bhardwaj, A. 2014, A\&A, 566, A134

Rousselot, P., Jehin, E., Manfroid, J., \& Hutsemékers, D. 2012, A\&A, 545, A24

Schleicher, D. G., \& Bair, A. N. 2011, AJ, 141, 177

Schleicher, D. G., Birch, P. V., \& Bair, A. N. 2006, BAAS, 38, 485

Stuhl, F., \& Welge, K. H. 1969, Can. J. Chem., 47, 1879

Takahashi, K., Takeuchi, Y., \& Matsumi, Y. 2005, Chem. Phys. Lett., 410, 196

Tseng, W.-L., Bockelée-Morvan, D., Crovisier, J., Colom, P., \& Ip, W.-H. 2007, A\&A, 467, 729

Weaver, H. A., Feldman, P. D., A'Hearn, M. F., Dello Russo, N., \& Stern, S. A 2011, ApJ, 734, L5

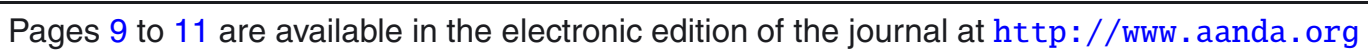


A. Decock et al.: [OI] lines in comets at various nucleocentric distances

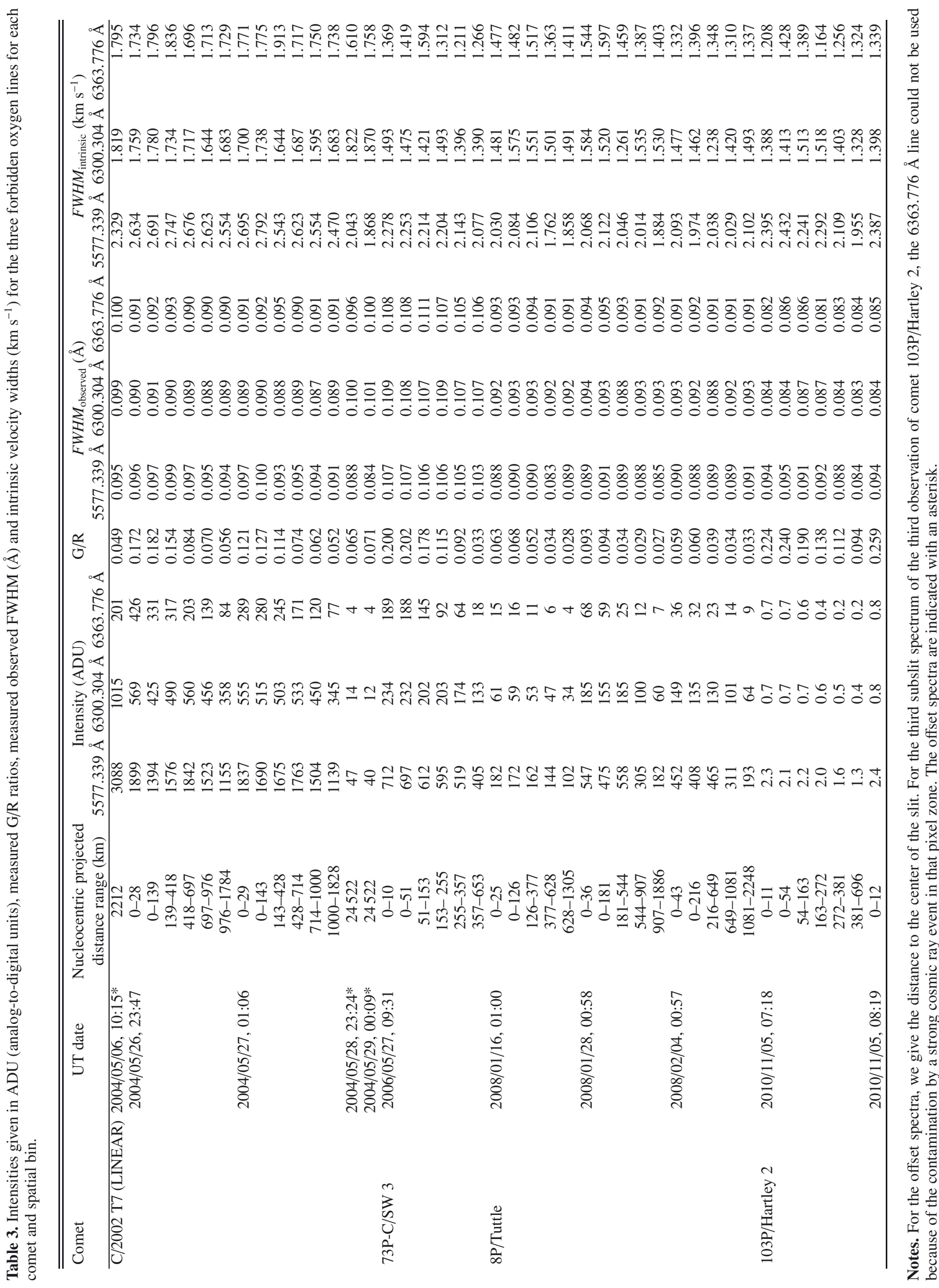




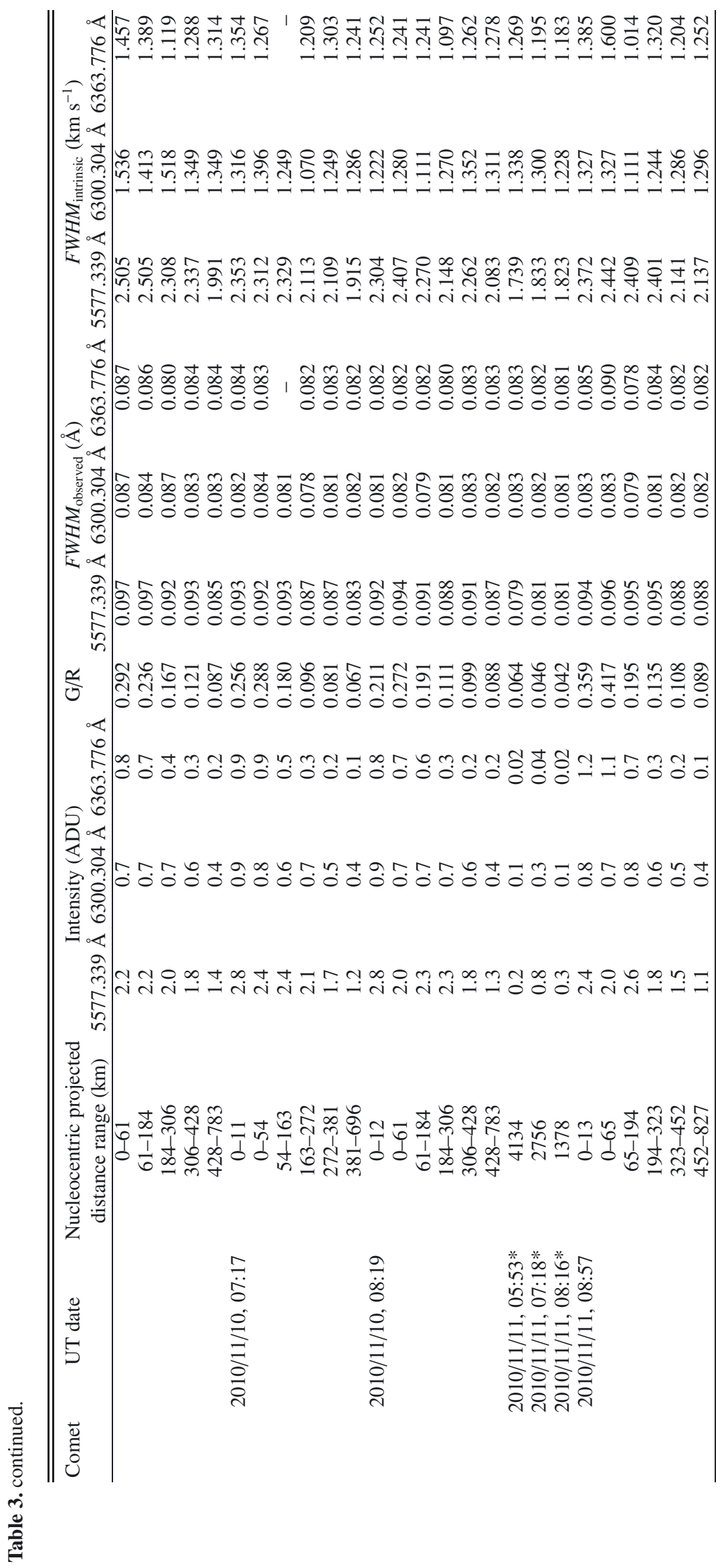


A. Decock et al.: [OI] lines in comets at various nucleocentric distances

Table 4. Average values of the G/R ratio and the intrinsic line FWHM for each spatial bin.

\begin{tabular}{|c|c|c|c|c|c|c|c|}
\hline \multirow[t]{2}{*}{ Comet } & \multirow[t]{2}{*}{ UT Date } & \multirow[t]{2}{*}{$N$} & \multirow{2}{*}{$\begin{array}{l}\text { Average nucleocentric } \\
\text { distance range }(\mathrm{km})\end{array}$} & \multirow[t]{2}{*}{$\mathrm{G} / \mathrm{R}$} & \multicolumn{3}{|c|}{$F W H M_{\text {intrinsic }}\left(\mathrm{km} \mathrm{s}^{-1}\right)$} \\
\hline & & & & & $5577.339 \AA$ & $6300.304 \AA$ & $6363.776 \AA$ \\
\hline \multirow[t]{8}{*}{ C/2002 T7 (LINEAR) } & $2004 / 05 / 06^{*}$ & 1 & 2212 & 0.049 & 2.329 & 1.819 & 1.795 \\
\hline & $2004 / 05 / 26-27$ & 2 & $0-29$ & $0.147 \pm 0.036$ & $2.664 \pm 0.043$ & $1.730 \pm 0.042$ & $1.752 \pm 0.026$ \\
\hline & & 2 & $0-141$ & $0.155 \pm 0.039$ & $2.741 \pm 0.072$ & $1.759 \pm 0.030$ & $1.785 \pm 0.015$ \\
\hline & & 2 & $141-423$ & $0.134 \pm 0.028$ & $2.645 \pm 0.144$ & $1.689 \pm 0.064$ & $1.875 \pm 0.054$ \\
\hline & & 2 & $423-706$ & $0.079 \pm 0.007$ & $2.649 \pm 0.037$ & $1.702 \pm 0.021$ & $1.706 \pm 0.015$ \\
\hline & & 2 & $706-988$ & $0.066 \pm 0.006$ & $2.589 \pm 0.048$ & $1.620 \pm 0.034$ & $1.731 \pm 0.027$ \\
\hline & & 2 & $988-1806$ & $0.054 \pm 0.003$ & $2.512 \pm 0.060$ & $1.683 \pm 0.000$ & $1.734 \pm 0.006$ \\
\hline & $2004 / 05 / 28-29^{*}$ & 2 & 24522 & $0.068 \pm 0.004$ & $1.955 \pm 0.123$ & $1.846 \pm 0.034$ & $1.684 \pm 0.105$ \\
\hline \multirow[t]{6}{*}{ 73P-C/SW 3} & $2006 / 05 / 27$ & 1 & $0-10$ & 0.200 & 2.278 & 1.493 & 1.369 \\
\hline & & 1 & $0-51$ & 0.202 & 2.253 & 1.475 & 1.419 \\
\hline & & 1 & $51-153$ & 0.178 & 2.214 & 1.421 & 1.594 \\
\hline & & 1 & $153-255$ & 0.115 & 2.204 & 1.493 & 1.312 \\
\hline & & 1 & $255-357$ & 0.092 & 2.143 & 1.396 & 1.211 \\
\hline & & 1 & $357-653$ & 0.033 & 2.077 & 1.390 & 1.266 \\
\hline \multirow[t]{5}{*}{ 8P/Tuttle } & $2008 / 01 / 16-28,02 / 04$ & 3 & $0-35$ & $0.072 \pm 0.019$ & $2.064 \pm 0.032$ & $1.514 \pm 0.060$ & $1.451 \pm 0.109$ \\
\hline & & 3 & $0-174$ & $0.074 \pm 0.018$ & $2.060 \pm 0.077$ & $1.519 \pm 0.057$ & $1.492 \pm 0.101$ \\
\hline & & 3 & $174-523$ & $0.042 \pm 0.009$ & $2.063 \pm 0.037$ & $1.350 \pm 0.175$ & $1.442 \pm 0.086$ \\
\hline & & 3 & $523-872$ & $0.032 \pm 0.003$ & $1.935 \pm 0.150$ & $1.485 \pm 0.059$ & $1.353 \pm 0.040$ \\
\hline & & 3 & $872-1813$ & $0.030 \pm 0.003$ & $1.948 \pm 0.134$ & $1.505 \pm 0.022$ & $1.383 \pm 0.040$ \\
\hline \multirow[t]{9}{*}{ 103P/Hartley 2} & 2010/11/05-10-11 & 5 & 0-12 & $0.262 \pm 0.058$ & $2.362 \pm 0.036$ & $1.330 \pm 0.071$ & $1.307 \pm 0.074$ \\
\hline & & 5 & $0-59$ & $0.302 \pm 0.068$ & $2.420 \pm 0.070$ & $1.276 \pm 0.047$ & $1.187 \pm 0.089$ \\
\hline & & 5 & $59-178$ & $0.198 \pm 0.022$ & $2.351 \pm 0.107$ & $1.279 \pm 0.180$ & $1.258 \pm 0.177$ \\
\hline & & 5 & $178-296$ & $0.129 \pm 0.027$ & $2.252 \pm 0.119$ & $1.324 \pm 0.193$ & $1.182 \pm 0.088$ \\
\hline & & 5 & $296-414$ & $0.104 \pm 0.015$ & $2.192 \pm 0.103$ & $1.328 \pm 0.061$ & $1.263 \pm 0.038$ \\
\hline & & 5 & $414-757$ & $0.085 \pm 0.010$ & $2.016 \pm 0.092$ & $1.314 \pm 0.025$ & $1.282 \pm 0.037$ \\
\hline & 2010/11/11, 05:53* & 1 & 4134 & 0.064 & 1.739 & 1.338 & 1.269 \\
\hline & $2010 / 11 / 11,07: 18^{*}$ & 1 & 2756 & 0.046 & 1.833 & 1.300 & 1.195 \\
\hline & $2010 / 11 / 11,08: 16^{*}$ & 1 & 1378 & 0.042 & 1.825 & 1.228 & 1.183 \\
\hline
\end{tabular}

Notes. The errors listed are the rms of the $N$ spectra available. 